\title{
Social Vulnerability Assessment to Flood in Medina Gounass Dakar
}

\author{
Ousmane Diouf Sané1*, Amadou Thierno Gaye², Moussa Diakhaté2, Mawuli Aziadekey³ \\ ${ }^{1}$ Université de Lomé, WASCAL, Département de Géographie, Lomé, Togo \\ ${ }^{2}$ Université Cheikh Anta Diop, Laboratoire de Physique de l'Atmosphère et de l'Océan Siméon Fongang \\ (LPAOSF), Dakar-Fann, Sénégal \\ ${ }^{3}$ Université de Lomé, Ecole Supérieure d'Agronomie, Lomé, Togo \\ Email: saneousmanediouf@gmail.com, atgaye@gmail.com, moussa1.diakhate@ucad.edu.sn, \\ guido.aziadek@gmail.com
}

Received 20 June 2015; accepted 14 August 2015; published 17 August 2015

Copyright (C) 2015 by authors and Scientific Research Publishing Inc.

This work is licensed under the Creative Commons Attribution International License (CC BY). http://creativecommons.org/licenses/by/4.0/

(c) (i) Open Access

\begin{abstract}
This paper is about the assessment of social vulnerability (SV) as a critical component of comprehensive disaster risk assessment. This study was conducted in Medina Gounass Dakar, Senegal, to bring out evidence that flooding was a threat to human security. The aim of this present study is to assess the social vulnerability to flood in Medina Gounass. Survey was carried out using structured questionnaires drawn on one hundred randomly selected households. For vulnerability assessment, the Methods for the Improvement of Vulnerability Assessment in Europe (MOVE) framework and Arc GIS are used to characterize vulnerability through three key factors, namely, 1) exposure, 2) susceptibility, and 3) lack of resilience. As a result, Medina Gounass inhabitants have a particular relationship with the place they have been living for decades. Although facing diseases and many challenges in their everyday life, people actually resist the government's relocation projects because of their symbolic relationship with the area.
\end{abstract}

\section{Keywords}

Assessment, Flood, Social Vulnerability, Medina Gounass

\section{Introduction and Context}

For centuries, human progress has depended on access to water in sufficient quality and quantity to make possible life on earth. This water has a great number of sources; the most common and known by almost everyone is

\footnotetext{
${ }^{*}$ Corresponding author.
}

How to cite this paper: Sané, O.D., Gaye, A.T., Diakhaté, M. and Aziadekey, M. (2015) Social Vulnerability Assessment to Flood in Medina Gounass Dakar. Journal of Geographic Information System, 7, 415-429. 
rainfall. Rainfall depends on the climate and it is known that the most brilliant civilisations that planet earth has ever known become prosperous in periods of favourable climate. Nowadays, this planet which produces the ecosystem services for human well-being has some disturbances in a pace that threatens the future of humankind. Thus, the earth is facing challenges, such as raising population, increasing desertification and, of course, climate change. Climate change, in IPCC (Intergovernmental Panel on Climate Change) usage, refers to a change in the state of the climate that can be identified (e.g., using statistical tests) by changes in the mean and/or the variability of its properties, and that persists for an extended period, typically decades or longer [1]. It refers to any change in climate over time, whether due to natural variability or as a result of human activities.

This usage differs from that in the United Nations Framework Convention on Climate Change (UNFCCC), where climate change refers to a change of climate that is attributed directly or indirectly to human activities that alter the composition of the global atmosphere and that is, in addition to natural climate variability, observed over comparable time periods [2]. This panel has a long history and periodically published key findings in the state of the climate. Their predictions anticipated more extreme, frequent and violent events, like droughts and floods. The occurrence of disasters linked to damages of physical events and social losses has a direct relationship with human existence. However, their frequency and damaging impacts are drastically increased during these last decades.

An increase in the number of persons, population density, infrastructure and production is located in hazardous areas and in conditions of such vulnerability they are more susceptible to excessive damage and loss and face considerable difficulties in coping [3]. Furthermore, the severity of the impacts of extreme and non-extreme weather and climate events depends strongly on the level of vulnerability and exposure to these events [4].

Generally, flooding occurs in periods of heavy rainfall. However, floods are not always caused by precipitations. In these last decades, many scholars from various disciplines are interested in the field of disasters caused by floods. In Africa for instance, the frequency of hydrological disasters represented $68.8 \%$ [5].

For instance, assessment of flood vulnerability in the city of Abeokuta in Nigeria during the flood event in 2007 used a questionnaire survey to reach its goals. In his study, flood vulnerability was assessed by examining exposure and susceptibility, and coping indicators in the study area. One of his key findings was that most of Abeokuta inhabitants did not anticipate a flood event of such magnitude to occur, despite its location on a flood plain and, therefore, they were unprepared for such hazard [6]. The specificity of our study area is that flooding becomes more acute over the years with flood water obstructing human activities and many structures situated within a flood plain. In this regard, Medina Gounass is essentially and illegally settled in to a large extent, and does not follow any planning. Medina Gounass is already at risk from periodic floods due to heavy rainfall events. Additionally, population mostly uses latrines with septic tanks [7]. The combination of these elements puts the area at risk. The social processes and their interaction with the environment lead its vulnerability against floods.

The concept of vulnerability has a multitude of definitions. This concept is fundamental to human-environment research. The word "vulnerability" is derived from the Latin word vulnerare, meaning "to wound". At a very basic level, vulnerability can be defined as "the capacity to be wounded" or the "potential for loss". Therefore, social vulnerability encompasses many aspects. It is not limited to social weaknesses to withstand a natural or man-made hazard but it includes social discrepancies in terms of food security, health security, and all the components of human security at large in the flooding situation. Social vulnerability is also directly linked to the environment in which people are living [8]. Additionally, social vulnerability refers to the socioeconomic and demographic factors that affect the resilience of communities [9].

Social vulnerability can have multiple forms: it can be the state of the system before the event, and the likelihood of outcomes in terms of economic losses and life lost, and it can also be the lack of capacities or weaknesses to face and recover quickly when the disaster strikes. The latter deals with the resilience of a system or a community to respond and recover with its internal means to the adverse impacts of the disaster. Studies on the social production of vulnerability as a central theme of research on the human dimensions of environmental change hold that vulnerability to environmental disasters is largely a product of the way that humans occupy and use the natural environment [10]. Moreover, four different levels have been identified when it comes to social vulnerability to natural hazard impacts [11]. Consequently, the assumption of social construction of risk becomes clearer. For that, the socio-natural co-production of hazard and the social qualities of vulnerability, and the ways in which different stakeholders perceive hazard, vulnerability and risk also need to be considered to understand the social construction of risk [12].

The occurrence of floods in the Dakar suburbs is a new phenomenon. The Senegalese capital is characterised 
by an out of control urbanisation process. Among the many impacts noted, flooding has appeared recently as a major threat to poor population leaving in the suburbs of Dakar. Nevertheless, the combination of population growth, lack of urban planning, and climatic conditions have led to an unprecedented flood disasters in different urban areas of Senegal [13]. It is in this context that the paper examines the realities of floods in Medina Gounass. This is done first by analysing rainfall indices at local level. Then, selected exposure, susceptibility, and lack of resilience indicators of sampled population through the MOVE framework have been mapped using Geography Information System (GIS). Lastly, the analysis of these indicators provides the social vulnerability characteristics of Medina Gounass inhabitants.

\section{Materials and Methods}

\subsection{Study Area}

Medina Gounass district is located between 14.769 latitude North and -17.387 longitude West in the Guédiawaye Department. It is limited in the North by the district of Sam Notaire and the Ndiarème Limamoulaye district; in the East by the district of Wakhinane Nimzath and to the South and West by the district of Djiddah Thiaroye Kao. Formerly, it belonged to the Pikine Department (Figure 1). The Guédiawaye department was created in 1990 following the decentralization law. Currently, it has five boroughs, including Medina Gounass which is located South-East of the city of Guédiawaye. It is by far the most densely populated district.

Medina Gounass has the smallest area $\left(1.1 \mathrm{~km}^{2}\right)$ but has the highest density of 31,086 inhabitants per square kilometre across the Guédiawaye department. The number of people living in the study area is not definitely established. It is mentioned 44,000 inhabitants while former Deputy Mayor of Medina Gounass has 43,000 inhabitants [7]. Now with the population movement, it is estimated at around 40,000 inhabitants. After the 2005 flood events, the former government has built a city not very far from Keur Massar to relocate people and this project was called "Plan Jaxay". The present government has done the same in another location in "Tivaouane

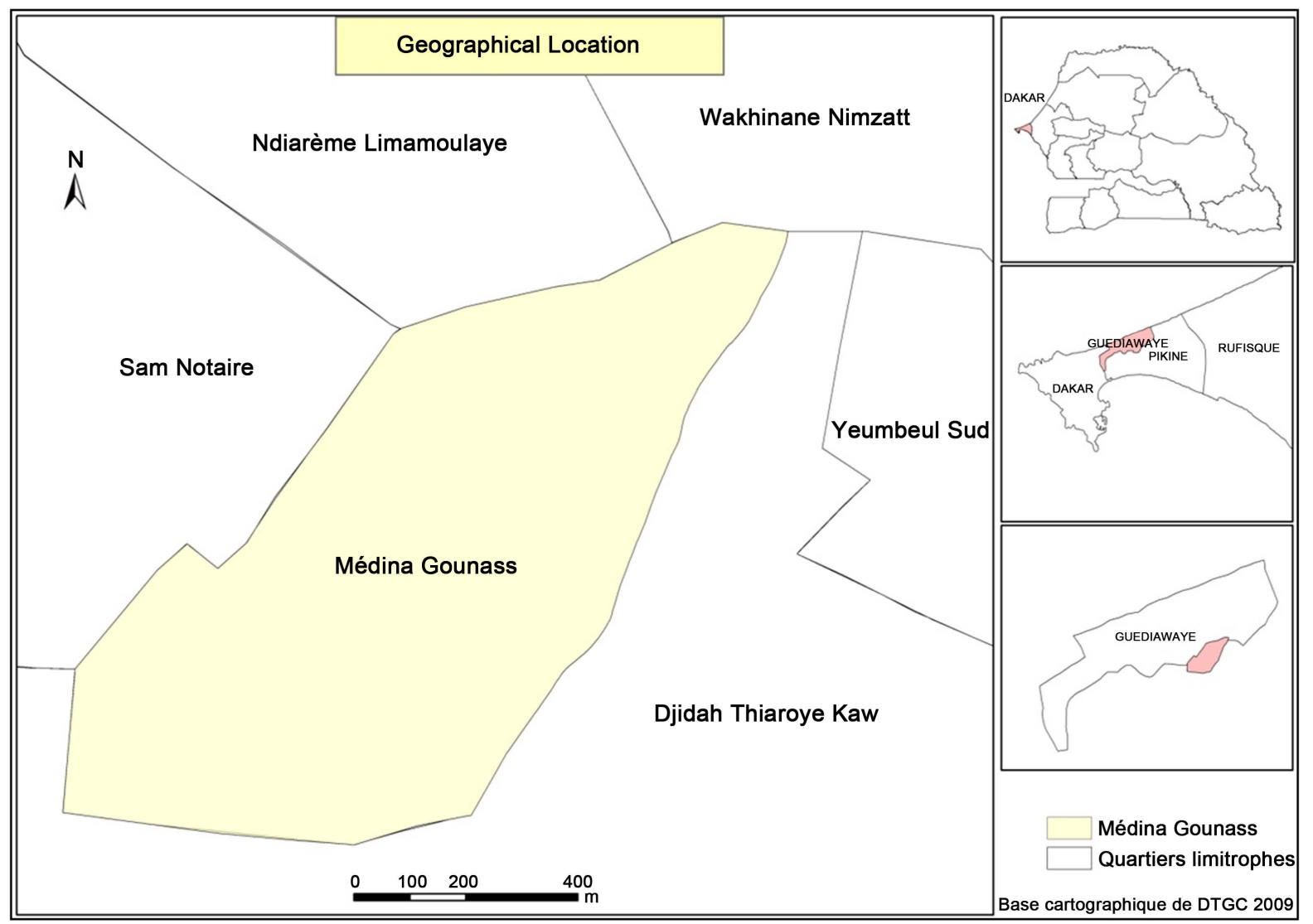

Figure 1. Geographical location of Medina Gounass. 
Peul" called Plan "Tawfekh" which is about 22 km North-East of Dakar, the country's capital and near to the Keur Massar administrative district.

Hydrologically, the watersheds of the district of Gounass are small in size. Degradation of the river system resulted in the formation of a chain of lakes or ponds. Flows are endorheic (having no outlet) as offshore bars prevent their escape to the Atlantic sea. Strong soil sealing in urban areas has changed the nature of runoff quantity (decrease losses flow, rapid movement of water). Over the past thirty years, this region has experienced very rapid urbanisation, linked to the rural exodus that climatic deterioration and degradation of living conditions in rural areas have caused in the entire Sahelian region [14].

Moreover, the ground water corresponds to outcropping geological formation consisting of sand dunes dating from the Quaternary or the continental terminal. These sands have been underlain by sedimentary geological formations [15].

\subsection{Methods and Data}

Social vulnerability includes the climatic conditions, socioeconomic status, household composition and disability.

Key factors of the MOVE framework are related to the exposure of a society or system to a hazard or stressor, the susceptibility of the system or community exposed, and its resilience and adaptive capacity (Figure 2). Also, this approach underlines the necessity to consider multiple thematic dimensions when assessing vulnerability in the context of natural and socio-natural hazards [12]. It is the case in the study area because flooding is not only caused by extreme events like a heavy rainfall but it is a combination of rapid urbanisation and anarchic settlement for decades that trigger natural hazard-associated risk that threatens human security globally. This theoretical framework shows the linkage between different concepts of disaster risk management and climate change adaptation and appears as a useful tool for communicating complexity; it stresses the need for societal change in order to reduce risk and to promote adaptation. Therefore, the MOVE framework makes a clear differentiation between risk and vulnerability and also deals with the integration of the concept of adaptation in vulnerability assessments to natural hazards [12].

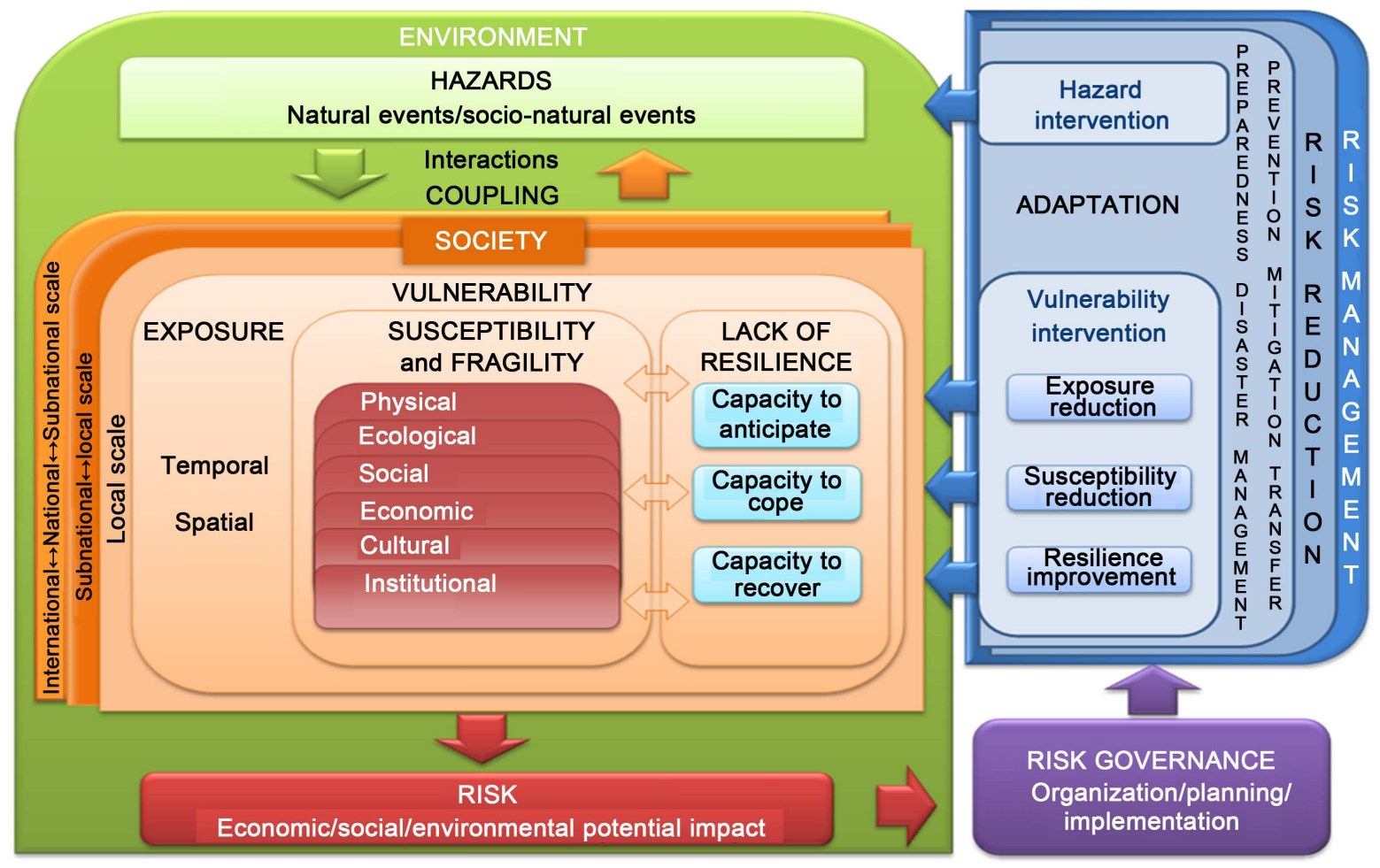

Figure 2. The MOVE framework of natural Hazards: Framing vulnerability, risk and societal responses. Source: Birkmann et al. (2013). 
Exposure describes the extent to which a unit of assessment falls within the geographical range of a hazard event. Susceptibility (or fragility) describes the predisposition of elements at risk (social and ecological) to suffer harm. The Lack of resilience or societal response capacity is determined by limitations in terms of access to, and mobilisation of, the resources of a community or a social-ecological system in responding to an identified hazard, whereas the adaptation box deals with the ability of a community or a system to learn from the past disasters and to change existing practices for potential future changes in hazards as well as vulnerability contexts.

The MOVE framework characterizes vulnerability through three key factors, namely, 1) exposure (E)-reflecting the extent to which a unit of assessment falls within the geographical range of a hazard event; 2) susceptibility (SUS) - which describes the predisposition of elements at risk to suffer harm; 3) lack of resilience (LoR), which is determined by limitations in terms of access to, and mobilization of, the resources of a community or social-ecological system in responding to a particular hazard. Based on data availability, previous research and personal judgement, the following indicators were selected under each vulnerability component (Table 1).

This table gives the functional relationship between the indicators and the vulnerability.

All datasets were standardized, using linear min-max normalization (Equations (1) and (2)) according to (Iyengar and Sudarshan) [16] [17]. When the indicators are related positively with the vulnerability, the normalized value of the indicator is computed as follow.

$$
X_{i j}=\frac{x_{i j}-\min \left(x_{i j}\right)}{\max \left(x_{i j}\right)-\min \left(x_{i j}\right)}
$$

When the indicators are related negatively with the vulnerability, the normalized value of the indicator is computed as follow.

$$
X_{i j}=\frac{\max \left(x_{i j}\right)-x_{i j}}{\max \left(x_{i j}\right)-\min \left(x_{i j}\right)}
$$

$X_{i j}$ is the normalized value of the indicator $i$ of the component $j$; $x_{i j}$, le value of the indicator $i$; $\max \left(x_{i j}\right)$ and $\min \left(x_{i j}\right)$ are respectively the maximum and minimum values of the indicators $i$ of the component $\mathrm{j}$.

It is assumed that there are $M$ regions or districts, $K$ indicators of vulnerability and $x_{i j}$ $(i=1,2, \cdots, M ; j=1,2, \cdots, K)$ are the normalized scores. The level of development of $i^{\text {th }}$ zone, $\overline{y_{i}}$ is assumed to be a linear sum of $x_{i j}$ as

$$
\overline{y_{i}}=\sum_{j=1}^{K} w_{j} x_{i j}
$$

where $w$ 's $\left(0<w<1\right.$ and $\left.\sum_{j=1}^{K} w_{j}=1\right)$ are the weights [16]. In Iyengar and Sudarshan's method, the weights are assumed to vary inversely as the variance over the regions is the respective indicators of vulnerability. That is, the weight $w_{j}$ is determined by

$$
w_{j}=\frac{c}{\sqrt{\operatorname{var}\left(x_{i j}\right)_{i}}}
$$

where $c$ is a normalizing constant such that

Table 1. Recapitulation of components, number of indicators and the functional relationship.

\begin{tabular}{cccc}
\hline Components & Number & Indicators & Functional relationship \\
\hline Exposure (E) & 1 & Household size & Positive \\
Susceptibility (SUS) & 1 & Number of children under 4 years & Positive \\
Lack of resilience (LoR) & 1 & Distance to nearest hospital & Positive \\
\hline
\end{tabular}




$$
c=\left[\sum_{j=1}^{j=K} \frac{1}{\sqrt{\operatorname{var}\left(x_{i j}\right)_{i}}}\right]^{-1}
$$

The choice of the weights in this manner would ensure that large variation in any one of the indicators would not unduly dominate the contribution of the rest of the indicators and distort inter regional comparisons.

The aggregation of the three components (i.e., E, SUS and LoR) into the final composite indicator of socioeconomic vulnerability was then performed using the equation below, while taking into account specific weights for the three components as detailed below:

$$
V U=\frac{\sum_{j=1}^{n} w_{j} x_{j}}{m}
$$

In the equation $V U$ refers to the vulnerability index for a given neighbourhood, $m$ equals the number of components, $w_{j}$ represents the weights for domain $j$ and $x_{j}$ is the index of component $\mathrm{j}$ (i.e., E, SUS, LoR). In this study, the three components have the same number of indicators. So, the weight $w$ is equal to 1 for each of them and $\mathrm{m}$ is represented by 3 . The vulnerability index so computed lies between 0 and 1 , with 1 indicating maximum vulnerability and 0 indicating no vulnerability at all.

Climate data involved in this study were monthly values of minimum and maximum temperatures and rainfall amount sorted by decades for the whole time series. These data are from the Dakar Yoff station and the dataset covers the time period 1947 to 2012. For the analysis, descriptive statistics for both monthly mean temperature and monthly total rainfall amount were firstly extracted. With Excel, the diagram average monthly mean temperature and rainfall is made.

The following formula is used for the Lamb index determination who proposed a rainfall analysis method named "rainfall anomaly index. This index is calculated by the following formula:

$$
X_{j}=\frac{1}{N_{j}} \sum_{i=1}^{N_{j}} \frac{r_{i j}+m_{i}}{\sigma_{i}}
$$

where $r_{i j}$ is the rainfall measured in a year $j$ at a station $i, m_{i}$ and $\sigma_{i}$ are respectively the average and standard deviation of the rainfall recorded at the station $i$, and $N_{j}$ is the number of stations that have recorded rainfall in the year $j$. Since the study area has one station (Dakar Yoff station), the above-mentioned formula becomes:

$$
X_{i}=\frac{r_{i}+m}{\sigma}
$$

where $X_{i}$ is the rainfall anomaly index for the year $i, r_{i}$ is the total annual rainfall for the year $i, m$ and $\sigma$ are respectively the average and standard deviation of the annual rainfall recorded during the period of time chosen for this study [18].

Quantitative method is used for the socio-economic analysis. The advantage of quantitative research is that the findings from the sample under study will more accurately reflect the overall population from which the sample was drawn [19]. For that, the sampling method and simplified formula is used to calculate sample size. A $95 \%$ confidence level and $P=5 \%, 7 \%$ or $10 \%$ are assumed for different population size by the equation below [20].

$$
n=\frac{N}{1+N(e)^{2}}
$$

where $n$ is the sample size, $N$ is the population size and $e$ is the level of precision. 44,000 people live in Medina Gounass our sample comprises 100 households, because we apply $P=10 \%$ with the formula above.

This research equally adopts an exploratory approach, using predominantly qualitative methods. Qualitative research provides a richer and more in-depth understanding of the population under study. Techniques such as interviews and focus groups allow research participants to give very detailed and specific answers [19].

EpiData, excel and the Statistical Package for the Social Sciences (SPSS) are used for data entry and statistical analysis for data analysis. For EpiData, questions should be coded in quantitative form so that it could be easily analysed. This software is very useful because it can allow us to convert different variables from the field survey to an excel file for the statistical analysis in SPSS. Thus Pie charts and bar graphs are drawn. 


\section{Results and Discussions}

\subsection{Results of Meteorological Data Analysis}

\section{Precipitation Analysis}

Generally speaking, precipitation in Sénégal is closely related to the one that prevails in the Sahel. It occurs with the advent of the African Monsoon. During the second half of May and June, the ITCZ (Intertropical Convergence Zone) is stable around 5 degrees north. It is the first rainy season in the Gulf of Guinea. While in July, the ITCZ has moved rapidly to the north, reaching its second equilibrium position at 10 degrees North and remains there until mid-August. It is the wet season in the Sahelian region [21]. Rainfall is by far the most crucial variable that influences the climate and people's lives. It is determinant to the changing environment in this region. Thus, it is the most suitable parameter to characterize and analyse climatic changes in the Sahel. Even though Sahelian lives depend on rainfall, extremes like floods are destructive for crops in agricultural activities and for human settlement in cities.

Figure 3 which is a combination of the monthly mean of rainfall and monthly mean of temperature from 1947 to 2012, shows how rainfall is distributed in Dakar. This confirms that July, August and September are the wettest months in Sénégal. They are also the periods where flood events occur mostly. Also, as it can be observed, the months of rainfall are the hottest in Dakar. Therefore, the monthly mean rainfall of July is around $70 \mathrm{~mm}$; $180 \mathrm{~mm}$ for August and $145 \mathrm{~mm}$ for September. August is the most pronounced in terms of rainfall. 105 millimetres $(\mathrm{mm})$ of rainfall are recorded in 24 hours which triggered flooding in Cities as Dakar $22^{\text {nd }}$ of July, 2000 and Saint-Louis on $1^{\text {st }}$ of August 2000 [18].

In the same vein, 2005 is characterised by the frequency of heavy rainfall within a short period. Therefore, with an annual total of $590 \mathrm{~mm}$ rainfall, $270 \mathrm{~mm}$ with a percentage of $46 \%$ have fallen within seven days in mid-August and $360 \mathrm{~mm}$ in fourteen days which represent $61 \%$ by the end of August and the beginning of September. Comparing these information with our data which are sorted per decade, in 2005, Dakar Yoff station recorded $188.9 \mathrm{~mm}$ and $145 \mathrm{~mm}$ for the second and third decades, respectively, for a monthly total of $336 \mathrm{~mm}$. In the first decade of September, $106.8 \mathrm{~mm}$ were recorded [22]. Furthermore, in July 2000 Dakar Yoff station has recorded $154.3 \mathrm{~mm}$ in the third decade. As a result, flooding in Medina Gounass is caused by heavy rainfall during a short time. Consequently, August and September are months in which local inhabitants suffer the most. This information confirms that these three months are the wettest where an important amount of rainfall is recorded in Dakar and the most pronounced month is August.

The annual rainfall index variation has a long history in climatology for the determination of dry years and wet years. For instance the Sahel drought was a recurrent concern for populations, hydrologists and ecologists. Actually, West Africa, as a whole, experienced a widespread drought in the 1970s and 1980s [23]. Thus, the decade 1990s saw a gradual return to more humid conditions of rainfall deficit over the Sahel, continued until 2002.

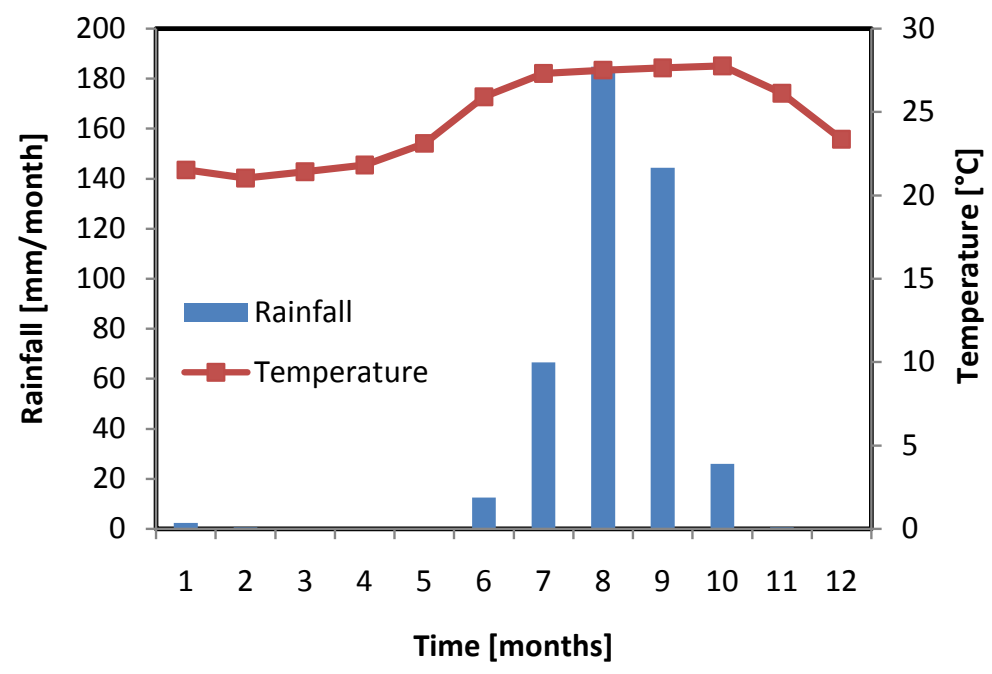

Figure 3. Dakar Yoff station monthly mean (1947-2012) temperature and rainfall. 
For this index, the negative values below -0.5 are considered dry years and positive values above 0.5 are wet years, the Lamb index used to perform rainfall analysis based on daily data precipitation collected at ten synoptic stations of Sénégal from 1921 to 2000 [18]. The choice of this series of rainfall lies in a preoccupation of doing a relevant analysis, which takes into account a long period before and after the onset of drought. Analysis of rainfall-floods events relationship is based only on the review of daily precipitation, regardless previous rainfall.

Furthermore, a survey has been conducted and using the same station data ranging from 1970 to 2009. Climate variability is obvious through the rainfall totals throughout the Sahel. Normalized standard deviation for Dakar-Yoff station can vary considerably from one year to another. This variability due to type of disturbances; squall lines and cyclonic disturbances in the atmosphere bring most of the rainfall in Dakar. Additionally, the rainfall trend is on an increase from 1970 to 2009 and shows positive differences during the 2000s [24]. Thus, with the extension of buildings in high pressure areas, floods are becoming more frequent. However, the 2005 flood affected districts that were not so far touch by floods. Houses in Hann-Marist, a well-planned area are particularly vulnerable to these increases in rainfall; Medina Gounass where people live haphazardly, was highly affected by these events.

Looking at Figure 4, it appears that the time series is not well distributed and it is shown by the mobile mean drawn in red. Even though the index is used to determine flood and drought years, this study puts emphasis on floods. To justify the relevance of this index, the field survey revealed that 1989 can be considered as a base line concerning the history of floods in the area. Nevertheless, in 2005, $450 \mathrm{~mm}$ of cumulative rainfall recorded in 24 hours in August 2005 caused a damaging flood in Dakar and its suburbs. For us, it's too much to record such a quantity of rainfall in a single day in Dakar [14]. The data we have did not say the same thing even though they are from the same meteorological station of Dakar Yoff. She over estimate this information because in our data, $336 \mathrm{~mm}$ of rainfall are recorded in the whole August 2005.

One might be tempted to say that we are at the end of the cycle of drought and beginning of a new wet phase in Sénégal, but it's too earlier to argue that it is the return period to wet years in Sénégal. As an example, in an interview during the data collection, the 2014 rainy season was forecasted by ANACIM (Agence National de l'aviation Civile et de la Meteorologie) to be a normal to deficit one. Thus, until the beginning of September, many areas in the country did not have much rainfall for agricultural activities.

A close observation of the Lamb index graph, suggests that there are wet years during the period 1947-1970 and 1970 to 1989 corresponds to a long period of dryness. This period corresponds to the long droughts which hit the Sahel in general. In 1989, there was a wet year and after that we fall again in drier years till the early 2000s where wet years seem to be more frequent. In this last decade, rainfall is not without negative consequences for urban inhabitants. Hence, Dakar suburban particularly those from Medina Gounass, are constantly on rain water mixed with sewage, and drainage water which obstruct people's activities. This particular aspect is emphasised that in August and September 2005, nearly 200,000 people in poor suburbs of Dakar had their feet in the water and were later displaced and resettled in precarious sanitary conditions [14]. As a result, it becomes a threat for human security generally.

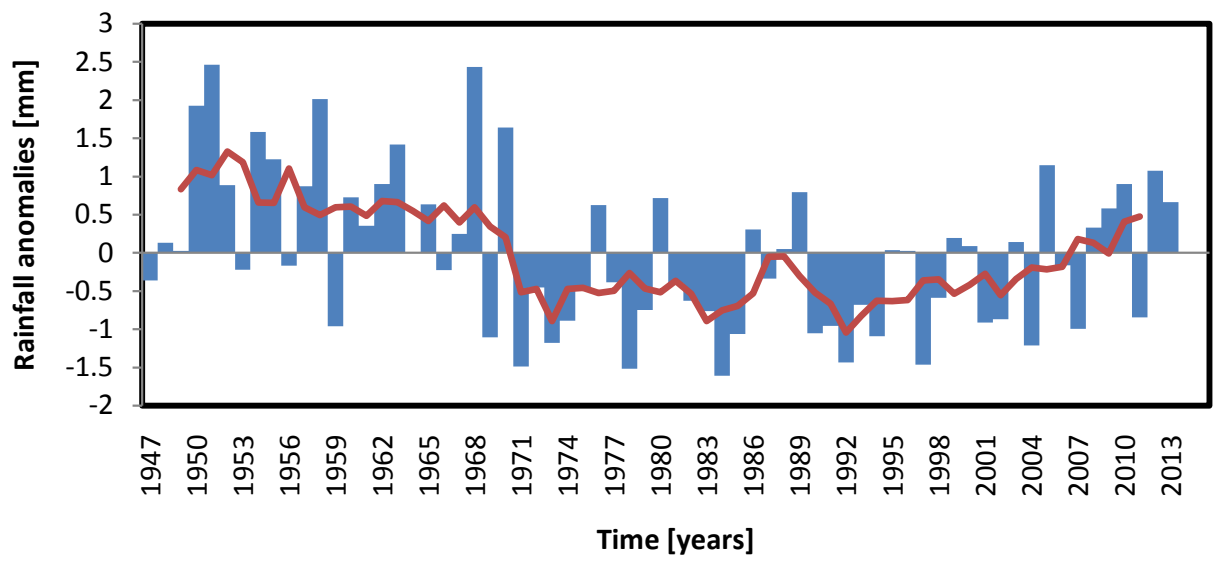

Figure 4. Annual rainfall index variation (Dakar Yoff Station). 


\subsection{Characteristics of the Sample}

The sample size of the survey is 100 household administrated within the study area. These filled questionnaires related to a certain number of social, economic, educational, environmental, and existential issue in the area where they live.

The education level shows sometimes the degree to which a community in able to withstand and recover quickly when a disaster strikes. Figure 5 illustrates the literacy rate of Medina Gounass inhabitants

In the same vein, the informal sector employs the youngest workers, the less educated and more females in Medina Gounass. This is also the area where we have the lower income, where social benefits are the lowest and the social welfare is almost null [14].

The literacy rate sometimes determines the level of income. Thus, Medina Gounass residents are not highly paid. Consequently, their level of income cannot allow them to afford housing in the well planned urban areas where viable and liable amenities already exist.

Figure 6 shows that those who have a salary paid in cash represent 39\%, for family support $18 \%$, job wage $25 \%$, other $5 \%$ and no answer $13 \%$. Linked to the literacy rate, these statistics confirm that the Medina Gounass inhabitants in general have limited economic means. Additionally, the survey reveals that the washrooms in the study area are not connected to the sewage. Only $8 \%$ are connected and $92 \%$ use the septic tanks. It is a real problem in this area because they are subject to recurrent flood events and the water table is not deep. When flooding occurs, the septic tanks' water and rain water flow together and affect populations.

It appears clearly in Figure 7 that the percentage of people having their own houses in Medina Gounass is by far greater than tenants, with $82 \%$ against $18 \%$. For a brief historical view, the site is a former crop fields space (Niayes) belonging to the Lebou ethnic group. They have sold the first plots of land for residential use at prices ranging between 3000 and 5000 CFA francs (less than 10 euros). People settled in regardless urbanisation standards [7]. Furthermore, the economic situation of Sénégal is characterised by an unequal wealth distribution and imbalance in the development level between western regions close to the capital city Dakar and those in the

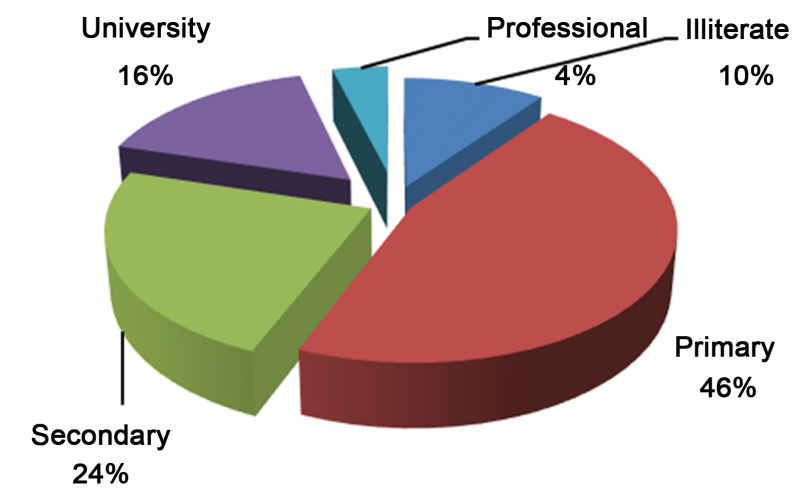

Figure 5. Literacy rate of Medina Gounass inhabitants.

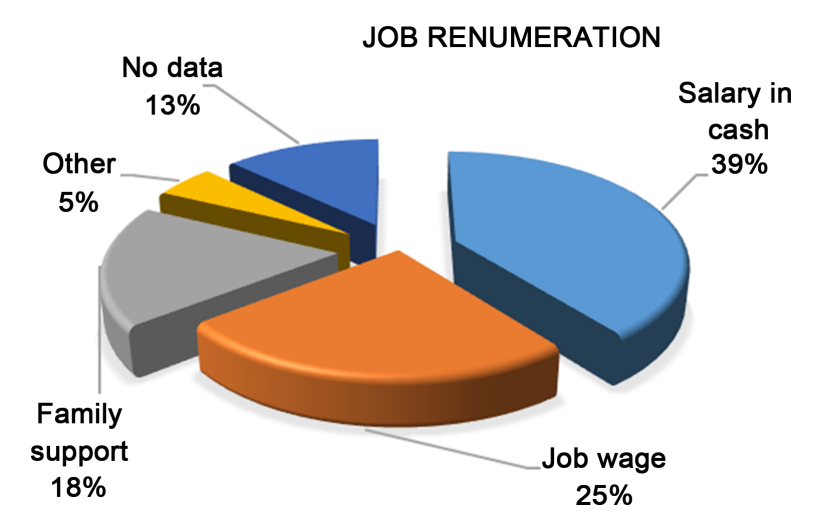

Figure 6. Job remuneration. 
East and the South. This situation is exacerbated by the droughts of 1972-1983 which generated inter-regional migration. The main migration flows are directed towards the Dakar region (49\% of flows in 1976) [25].

These situations are the driving forces behind the high population density in many suburbs including Medina Gounass. The socio-economic situation, the governance issues and climatic conditions encouraged people to settle haphazardly in these areas and no one at that time could imagine what would happen if there is a return period of rainfall. Additionally, the population growth in an unplanned site aggravated people's suffering during flood events. The land ownership was so cheap that people with moderate income prefer to have their houses in that risky area. These factors put Medina Gounass populations in a permanent situation of human insecurity.

Thus, the main driving force behind generates social inequities which are exacerbated by governance leniency, lack of preventive measures, bad behaviours and risk unawareness. "The inability to sustain stresses is produced by on-the-ground social inequality, unequal access to resources, poverty, poor infrastructure, lack of representation, and inadequate systems of social security, early warning, and planning. These are the factors that translate climate vagaries into suffering and loss" [26]. This statement summarises what happens in the study area. As a matter of fact, they have a strong symbolic relationship towards land they have struggled to obtain. It has become difficult for them to leave for an unknown land with many uncertainties. Hypothetically, flood-affected people settled within that area because they are mostly low-income people that could not afford housing on the urban-planned sites dotted with liable amenities. The situation of land ownership is important but not the only determinant to assess social vulnerability in Medina Gounass.

Internal mobility to access critical infrastructures is important too. Figure 8 shows the average time one has to spend to reach a certain number of critical infrastructures. For instance, those who do not have a tap at home spend on average five minutes to get water. Moreover, access to the nearest market is too important and the average time to get to nearest market is about twenty minutes.

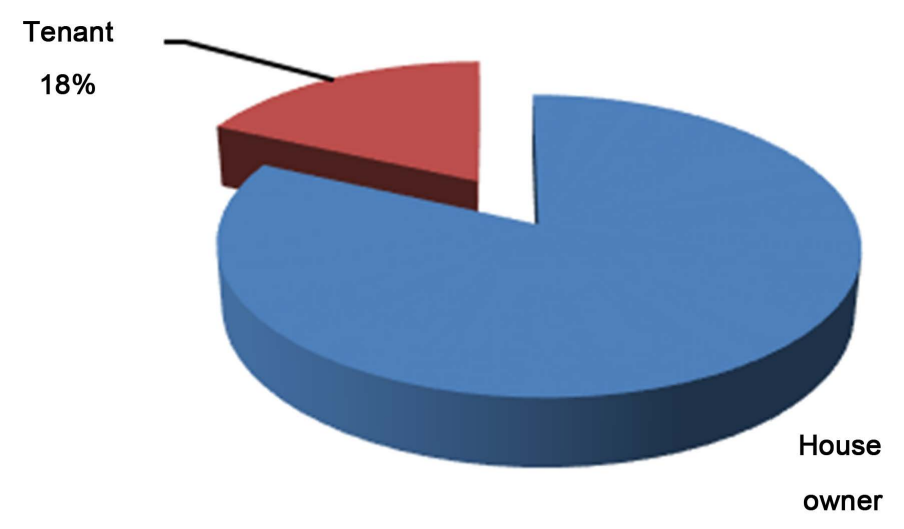

$82 \%$

Figure 7. House ownership and tenant in Medina Gounass.

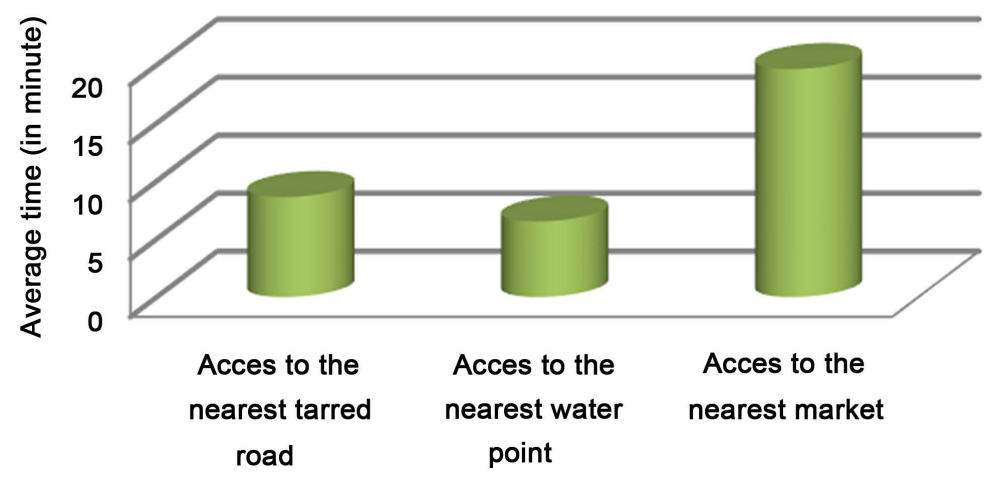

Figure 8. Average time to reach some critical infrastructures as tarred road, the nearest market, and the nearest public tap. 


\subsection{Vulnerability Analysis}

The exposure is the first element analysed and it is determined by the size of household.

The exposure (Figure 9) shows that the most exposed population to adverse impacts of floods by the family size is spread out all over Medina Gounass. It is ranked from very lowly to very highly expose. The green bullets represent very low whereas red ones mean very high vulnerability to flood. However, the major part of the most exposed are grouped in the South, the Centre and the East-Northern part of the area. It is materialised by red bullets with a very high degree of household exposition to floods. Therefore, the spatial distribution of exposition to adverse consequences to floods in the precise case depends on the number of persons within the household. As a result, large families become a heavy burden when a disaster strikes in this area.

The susceptibility index is composed of the number of children less than 4 years of age in a given household. These households have the predisposition to suffer the most harm due to flood events during the rainy season. The susceptibility as highlighted in Figure 10 is sparsely distributed in the South, the South-East, and the Centre and in the East-North. It is also ranked from very low to very high. Some households are very highly susceptible because they have an important number of children less than four years who are known to be fragile to recurrent flood events in Medina Gounass. Humidity and water borne diseases such as cholera and water related diseases like malaria are very dangerous to this age group. In addition, they are low income people; thus they hardly take care of their children in terms of health. This spatial distribution is due to the fact that Medina Gounass is densely populated and sometimes families are parked within a small piece of land with a great number of people in a small house.

The lack of resilience is determined by the distance from the nearest health centre within Medina Gounass. Therefore, the nearer the household to the health centre, the higher their resilience is. In contrast, the farther a household from the health centre the lower is the resilience and, by extension, the higher the vulnerability in terms of health. The households located in the North and North-East are highly vulnerable, and those from the East and South experience medium vulnerability. These households living permanently in flood situation during the rainy seasons encounter many challenges regarding their health (Figure 11). This main aspect calls for their

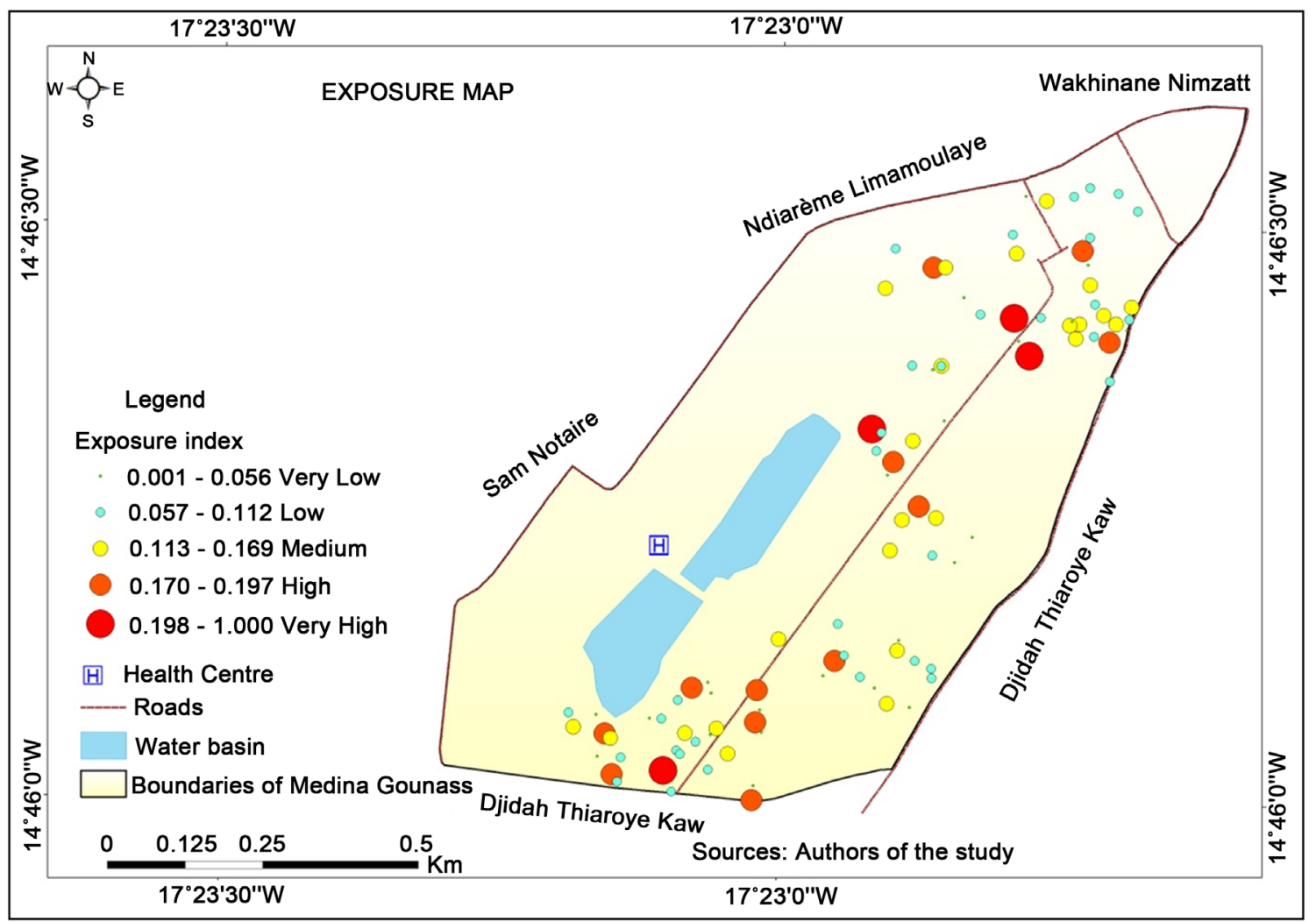

Figure 9. Exposure map of Medina Gounass determined by the household size. 


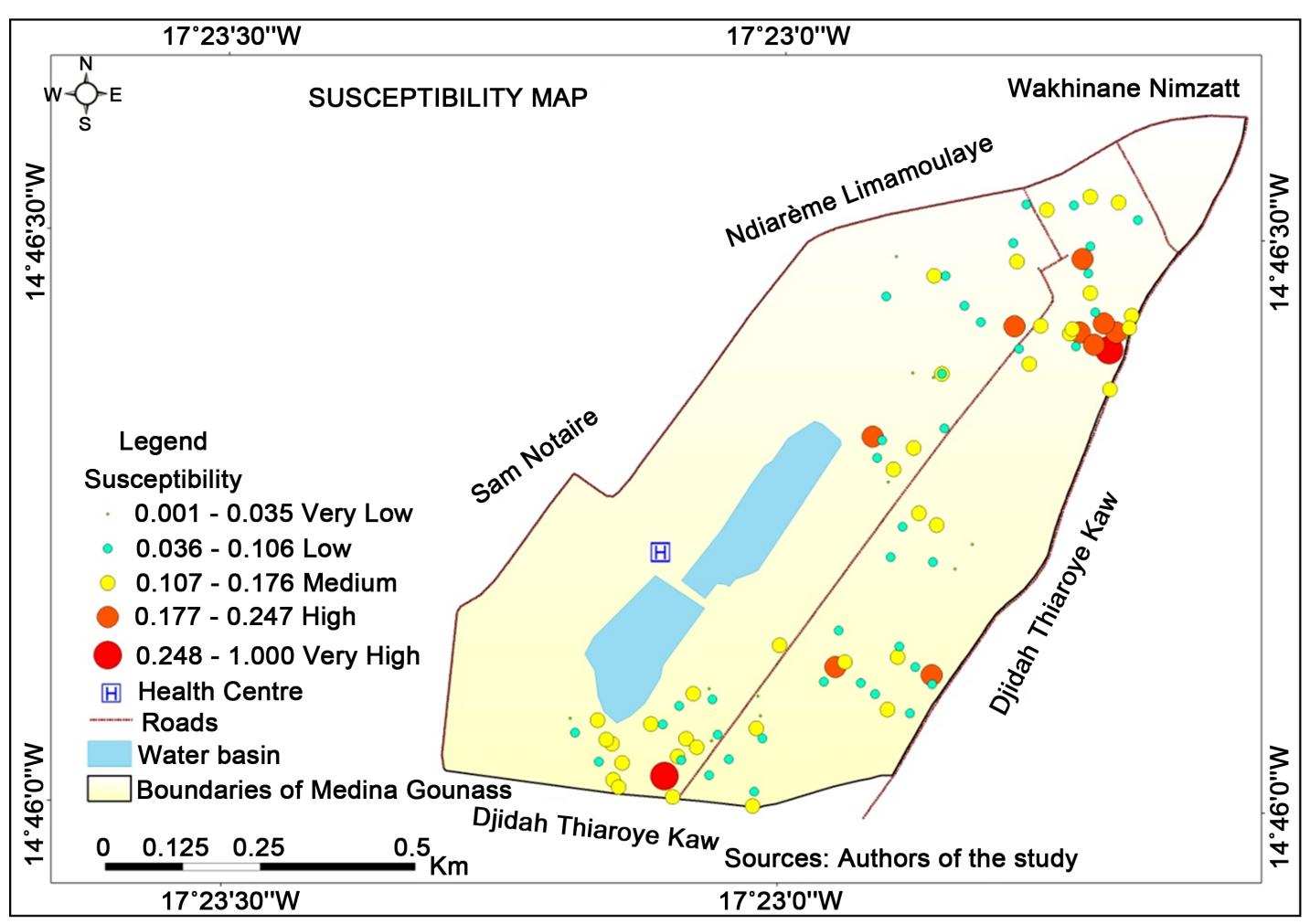

Figure 10. Suspectibility map of Medina Gounass.

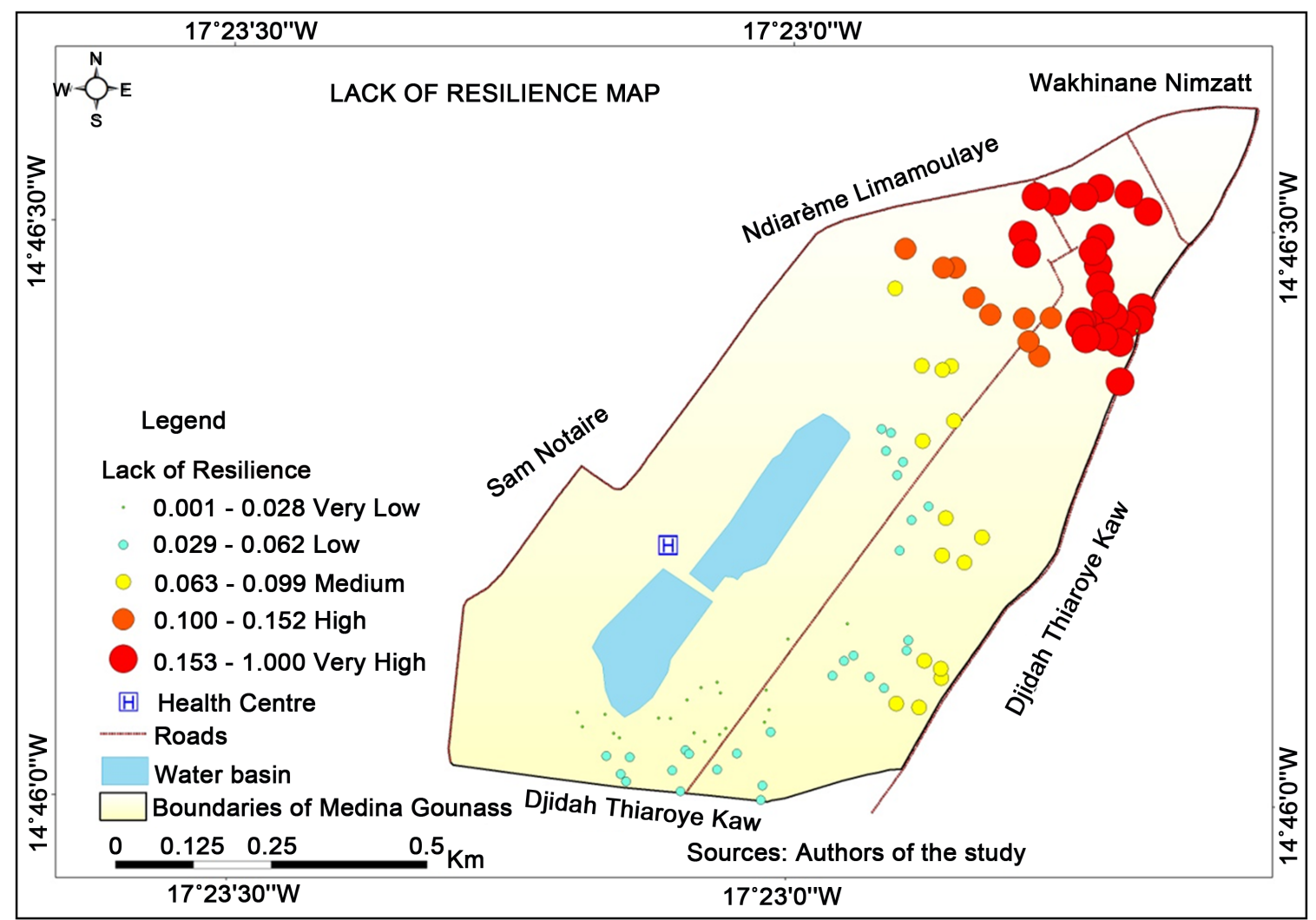

Figure 11. Lack of resilience map of Medina Gounass. 
capacity to anticipate, cope and recover from the adverse effects of recurrent flood events. Medina Gounass inhabitants are not resilient.

The survey and the focus group interviews showed that people use bags of sand and power-driven pumps to fight against floods. These measures are not sustainable because they did not offer perspective for the future. These power-driven pumps are provided by the government which spends money for fuelling and monitoring flood events instead of putting in place sustainable adaptation measures. Additionally, an old person notes during our interview in managing flooding events, those who have means put a great quantity of sand near their houses, generating conflicts in the neighbourhood.

These actions block the water ways and water enter in the houses of those who do not have means to do so. Sometimes, conflicts are so violent that the police have to intervene. As a result, flood generates conflicts between friends and relatives. In such situations, individualism prevails over the community.

However, the description of the results obtained through the spatial analysis for all single and composite indicators are aggregated for the calculation of the final map of vulnerability.

The combination of the three composite indicators shows the vulnerability of people living in Medina Gounass to floods. The interactions of these three major aspects of the MOVE framework are a crucial part of vulnerability assessment. From the map above, one can observe a concentration of the biggest bullets in the NorthEastern part of Medina Gounass. This result is not surprising because this part is a low land compared to other part of Medina Gounass. Additionally, they are the farthest from the health centre and the interview I conducted with the former Deputy Mayor details the new project of the construction of a basin at that place in order to collect the running waters in the area. This project can reduce considerably the social vulnerability of Medina Gounass to floods. Furthermore, Medina Gounass is among precarious neighbourhoods that suffer from the lack of drainage network wastewater and storm water. The streets are narrow and winding and do not facilitate fast and safe movement of people and goods. Thus, flooding is the most obvious risk in these illegal settlements and is a latent scourge behind much vulnerability and especially in rainy season. Based on rainfall, topographic criteria, hydrogeological, environmental and hygiene, Medina Gounass is one of the most affected areas. Although Medina Gounass belongs to the city of Guédiawaye, located on a dune site where soils are more permeable and therefore the infiltration of runoff is more obvious $75 \%$ of its area is flooded. In 2005,911 houses were flooded [14].

As a result, social vulnerability index in Figure 12 to floods is not solely limited to the set of indicators assessed. The reason for this restriction is due to the absence and lack of accurate data to have a more composite index. However, the household size for the exposure, children less than four years of age for susceptibility and the distance from the nearest health centre for the lack of resilience appear to be relevant in assessing the social vulnerability of the community to flood.

\section{Conclusions}

Medina Gounass is really vulnerable to floods. This vulnerability is not solely related to climatic conditions but it is a combination of a set of factors. The analysis of climatic data highlights a raise in temperature from May to October where the peak reaches. Consequently, in Dakar, the hottest month is October. Thus, temperature parameter cannot solely determine the changing climate. Therefore, rainfall data have been used jointly and the reason is that precipitation in Sénégal is related to the one of the Sahel. Then, rainfall is by far the most crucial variable on the climate and people's lives.

Extreme rainfall is one of the manifestations of climate change which causes floods events. Hence, Dakar suburban particularly those from Medina Gounass are constantly on rain waters mixed with sewage and drainage water which obstruct people's activities and become a threat for human security generally.

Moreover, the survey highlights that those who have a salary paid in cash represent 39\%, family support $18 \%$, job wage $25 \%$, other $5 \%$ and no answer $13 \%$. So they are not highly paid. The statistics with the linkage to the literacy rate confirm that the Medina Gounass inhabitants in general have limited economic means to buy houses elsewhere where the amenities already exist. Additionally, Medina Gounass lacks amenity plan for a district which is said to be on its own.

Finally, the social vulnerability index to floods is limited to a few numbers of indicators. The reason for this restriction is due to the absence and lack of accurate data to have a more composite index. However, the household size for the exposure, children under four years of age for susceptibility and the distance from the nearest 


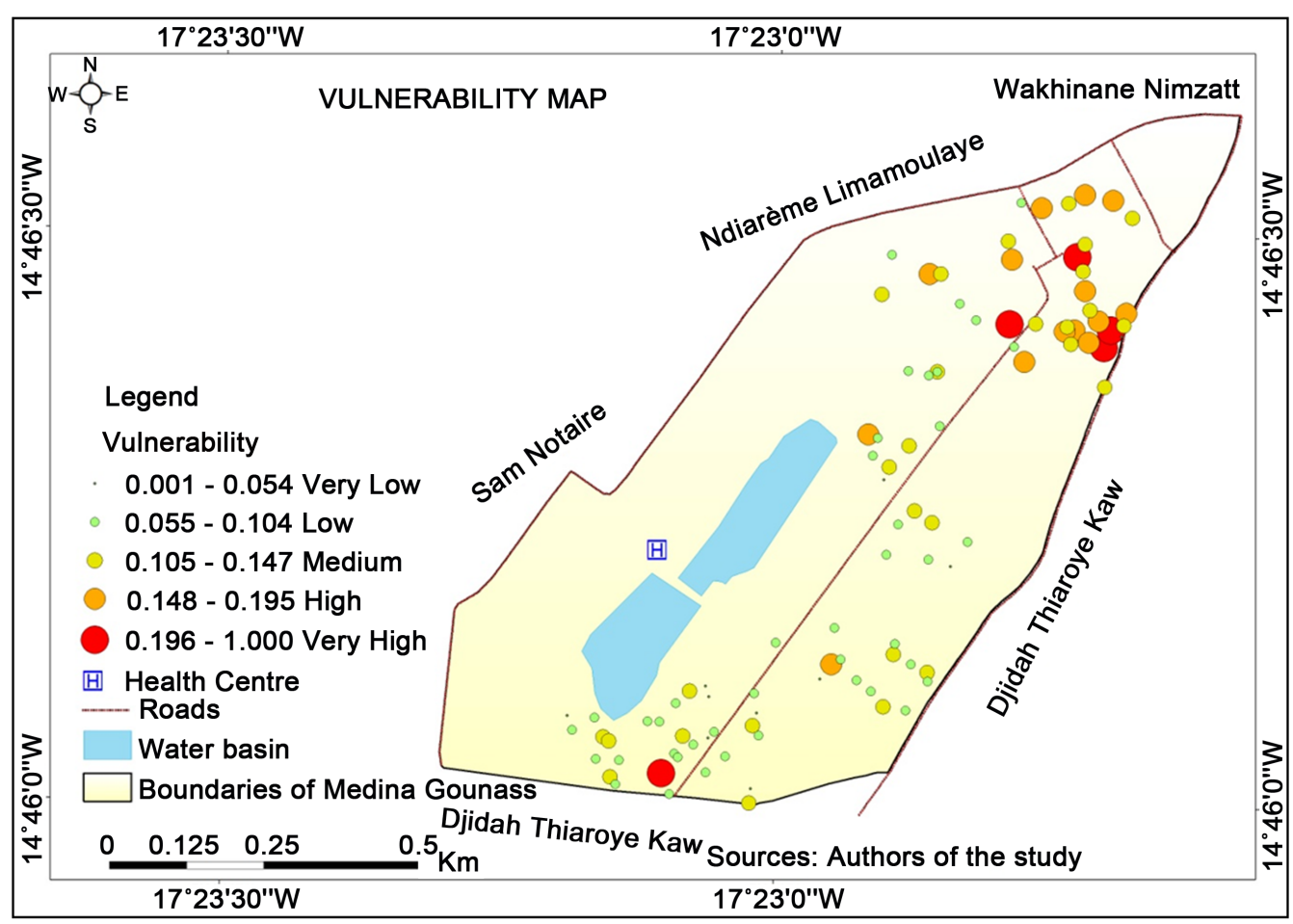

Figure 12. Vulnerability map of Medina Gounass.

health centre for the lack of resilience appear to be relevant in assessing the vulnerability of community to flood. As a result, flooding in Medina Gounass through this study shows how inhabitants are in a tricky situation and it is a real threat for human security.

\section{Acknowledgements}

We express our thanks to WASCAL, BMBF, ANACIM, Kouami Kokou, Boubacar Sane (Keba), Benilde Oudiane, Gadedjisso-Tossou Agossou, and M. Lamine Diop.

\section{References}

[1] IPCC (2007) Climate Change 2007: Impacts, Adaptation and Vulnerability. Synthesis report. Contribution of Working Group II to the Fourth Assessment Report of the Intergovernmental Panel on Climate Change. Cambridge University Press, Cambridge.

[2] UNFCCC (United Nations Framework Convention on Climate Change) (2007) Climate Change: Impacts, Vulnerabilities and Adaptation in Developing Countries. Climate Change Secretariat (UNFCCC), Bonn.

[3] Lavell, A. (2003) Local Level Risk Management: Concept and Practices. CEPREDENAC-UNDP, Quito.

[4] Cardona, O.D., van Aalst, M.K., Birkmann, J., Fordham, M., McGregor, G., Perez, R., Pulwarty, R.S., Schipper, E.L.F. and Sinh, B.T. (2012) Determinants of Risk: Exposure and Vulnerability. In: Field, C.B., Barros, V., Stocker, T.F., Qin, D., Dokken, D.J., Ebi, K.L., Mastrandrea, M.D., Mach, K.J., Plattner, G.-K., Allen, S.K., Tignor, M. and Midgley, P.M., Eds., Managing the Risks of Extreme Events and Disasters to Advance Climate Change Adaptation, A Special Report of Working Groups I and II of the Intergovernmental Panel on Climate Change (IPCC), Cambridge University Press, Cambridge and New York, 65-108. http://dx.doi.org/10.1017/cbo9781139177245.005

[5] Guha-Sapir, D., Vos, F., Below, R., Sylvain P. (2011) Annual Disaster Statistical Review 2011. Centre for Research on the Epidemiology of Disasters (CRED), Institute of Health and Society (IRSS), Université catholique de Louvain, Brussels.

[6] Adelekan, I.O. (2011) Vulnerability Assessment of an Urban Flood in Nigeria: Abeokuta Flood 2007. Nat Hazards, 56, 215-231. http://dx.doi.org/10.1007/s11069-010-9564-z

[7] Djigo, A.A. (2005) Population et Environnement : Assainissement des Eaux Usées et son Impact sur la Situation Socio 
Sanitaire des Populations de Medina Gounass. Mémoire en Population Développement et Santé de la Reproduction.

[8] Rygel, L., O'sullivan, D. and Yarnal, B. (2006) A Method for Constructing a Social Vulnerability Index: An Application to Hurricane Storm Surges in a Developed Country. Springer, 11, 741-764. http://dx.doi.org/10.1007/s11027-006-0265-6

[9] Flanagan, B.E., Gregory, E.W., Hallisey, E.J., Heitgerd, J.L. and Lewis, B. (2011) A Social Vulnerability Index for Disaster Management. Journal of Homeland Security and Emergency Management, 8, 1-22. http://dx.doi.org/10.2202/1547-7355.1792

[10] O'Brien, K. and Barnett, J. (2013) Global Environmental Change and Human Security. The Annual Review of Environment and Resources, 38, 373-391. http://dx.doi.org/10.1146/annurev-environ-032112-100655

[11] Dwyer, A., Zoppou, C., Nielsen, O., Day, S. and Roberts, S. (2004) Quantifying Social Vulnerability: A Methodology for Identifying Those at Risk to Natural Hazards. Geoscience Australia Record 2004/14.

[12] Birkmann, J., Cardona, O.D., Carreño, M.L., Barbat, A.H., Pelling, M., Schneiderbauer, S., Kienberger, S., Keiler, M., Alexander, D., Zeil, P. and Welle, T. (2013) Framing Vulnerability, Risk and Societal Responses: The Move Framwork. Nat Hazards, 67, 193-211. http://dx.doi.org/10.1007/s11069-013-0558-5

[13] Mbow, C., Diop, A., Diaw, A.T. and Niang, C.I. (2008) Urban Sprawl Development and Flooding at Yeumbeul Suburb (Dakar-Senegal). African Journal of Environmental Science and Technology, 2, 75-88.

[14] Priem, M. (2009) L'Efficience des Plans et Programmes d'Aménagement dans la Lutte contre les Inondations à Dakar: Zoom sur le Quartier de Medina Gounass. Mémoire de Master en Sciences et Gestion de l'Environnement, Université Libre de Bruxelles.

[15] Ndao, M. (2012) Dynamiques et gestion environnementales de 1970 à 2010 des zones humides au Sénégal: Etude de l'occupation du sol par télédétection des Niayes avec Djiddah Thiaroye Kao (à Dakar), Mboro (à Thiès) et Saint-Louis. PhD These, Universite de Toulouse, Toulouse.

[16] Iyengar, N.S. and Sudarshan. P. (1982) A Method of Classifying Regions from Multivariate Data. Economic and Political Weekly, 17, 2048-2052.

[17] Kumar, P., Paul, K.S.R., Kruhna, R.K., Rao, D.V.S. and Chandra, S.R.M. (2014) Assessment of Vulnerability and Impact of Climate Change on Crop Production in Krishna River Basin of Andhra Pradesh. International Journal of Current Agricultural Research, 3, 062-066. http://dx.doi.org/10.5958/i.0976-058X.48.1.011

[18] Sene, S. and Ozer, P. (2002) Évolution Pluviométrique et Relation Inondations-Événements Pluvieux au Sénégal. Bulletin de la Société Géographique de Liège, 42, 27-33.

[19] Vanderstoep, S.W. and Johnston, D.D. (2009) Research Methods for Everyday Life Blending Qualitative and Quantitative Approaches. Jossey-Bass, San Francisco.

[20] Israel, G.D. (2013) Determining Sample Size. Institute of Food and Agricultural Sciences (IFAS), University of Florida. PEOD-6, 1-5.

[21] Sultan, B., Baron, C., Dingkuhn, M., Sarr, B. and Janicot, S. (2005) Agricultural Impacts of Large Scale Variability of the West African Monsoon. Agricultural and Forest Meteorology, 128, 93-110. www.sciencedirect.com http://dx.doi.org/10.1016/j.agrformet.2004.08.005

[22] Wade, S., Faye, S., Dieng, M., Kaba, M. and Kane, N.R. (2009) Télédétection des Catastrophes d'Inondation urbaine: Le Cas de la Région de Dakar (Sénégal). Journées d'Animation Scientifique (JAS) de L'AUF, Alger, 1-7.

[23] Balme, M., Lebel, T. and Abou, A.A. (2006) Années sèches et années humides au Sahel: Quo vadimus? Hydrological Sciences Journal, 51, 254-271. http://dx.doi.org/10.1623/hysj.51.2.254

[24] Diop, C. and Sagna, P. (2011) Vulnérabilité Climatique Des Quartiers De Dakar Au Sénégal: Exemples De NordFoire-Azur Et De Hann-Maristes. Proceedings of the Renforcer la Résilience au Changement Climatique des Villes: Du Diagnostic Spatialisé Aux Mesures D’adaptation, Université Paul Verlaine, Metz, 7-8 Juillet 2011, 1-41.

[25] Sarr, C. (2010) Stratégie du Plan Jaxaay pour la Gestion des Inondations et la Recomposition des Zones Inondées dans la Banlieue Dakaroise: Cas de la Commune d'Arrondissement de Médina Gounass. Faculté des Lettres et Sciences Humaines Département de Géographie (UCAD), Mémoire Aménagement du Territoire, Décentralisation et Développement Local (Atddl).

[26] Ribot, J. (2013) Risk and Blame in the Anthropocene: Multi-Scale Climate Change Analysis. Proceedings of the International Conference on Food Sovereignty: A Critical Dialogue, Yale University, New Haven, 14-15 September 2013, 1-47. 